\title{
Overtubes and foreign bodies
}

\author{
NORMAN E MARCON, MD, FRCPC
}

\begin{abstract}
The most common article ingested in adults is food or food products such as nuts, shells, pits and bones. Poorly chewed steak causing bolus obstruction occurs especially in the elderly, while coins are most common in the pediatric group. New techniques of flexible endoscopy have altered and improved management, decreasing the need for surgery. A foreign body in the esophagus mandates prompt removal to avoid perforation. At least $80 \%$ of foreign bodies reaching the stomach pass spontaneously. Once the foreign body is beyond the distal duodenum, it should be followed with serial $\mathrm{x}$-rays. Techniques of removal of meat, bones, shells, bezoars, glass, bottle tops, sharps, pencils, pens, wires, thermometers, gastrostomy tubes, obesity balloons, safety pins, razor blades, button batteries and cocaine packets are described. Complications related to foreign body removal are rare. Can J Gastroenterol 1990;4(9):599-602
\end{abstract}

Key Words: Endoscopy, Foreign bodies, Overtubes

\section{Tubes protecteurs et corps étrangers}

RESUME: Les corps étrangers les plus fréquemment ingérés par les adultes sont de source alimentaire (noix, coquilles, noyaux, os et arêtes de poisson). Les steaks mal mastiqués sont la cause majeure d'obstruction chez les personnes âgées tandis que les pièces de monnaie figurent à l'inventaire du groupe pédiatrique. Les nouvelles techniques d'endoscopie souple ont transformé et amélioré le traitement des problèmes en question et diminué la nécessité des interventions chirurgicales. Il est impératif de retirer promptement de l'oesophage tout corps étranger susceptible d'entraîner une perforation. Plus de $80 \%$ des corps étrangers qui atteignent l'estomac sont évacués spontanément. Le corps étranger qui a franchi le duodénum devrait être sous surveillance radiologique. Le présent article décrit les techniques utilisées pour retirer divers corps étrangers (morceaux de viande, os, arêtes de poisson, coquilles, bézoards, verre, capsules de bouteille, esquilles, crayons, stylos, fils, thermomètres, tubes de gastrostomie, ballonnets utilisés dans le traitement de l'obésité, épingles de sûreté, lames de rasoir, piles de lithium et sachets de cocaïne). Les complications résultant de telles mesures sont rares.

Division of Gastroenterology, The Wellesley Hospital, Toronto, Ontario

Correspondence and reprints: Dr Norman E Marcon, 121 Jones Building, The Wellesley Hospital, 160 Wellesley Street East, Toronto, Ontario M4Y 1J3. Telephone (416) 926-7763
$\mathrm{F}$ OREIGN BODY INGESTION IS A common clinical problem, and the reasons for it are multiple. Adults who intentionally ingest a foreign body frequently have psychiatric disorders, mental retardation or alcoholism, or are prisoners seeking secondary gain. Children frequently ingest foreign bodies while at play. Accidental ingestion in adults occurs because of careless rapid eating, poor eyesight, alcohol ingestion or the use of dentures which interfere with adequate sensation in the palate. The most common article ingested is food or its products, such as nuts, shells, pits and bones. Poorly chewed steak causing bolus obstruction occurs especially in the elderly (1). Coins are most common in the pediatric group (2).

In the past, ingested foreign bodies would frequently require surgical removal. New techniques of flexible endoscopy (3) and a better understanding of the natural history of foreign body ingestion and passage have altered and improved management.

Since the widespread availability of fibreoptic endoscopes, a wide range of foreign bodies have been removed from the gut. Many have been removed with flexible endoscopes on an ambulatory basis with sedation only. However, young children or agitated adults way 


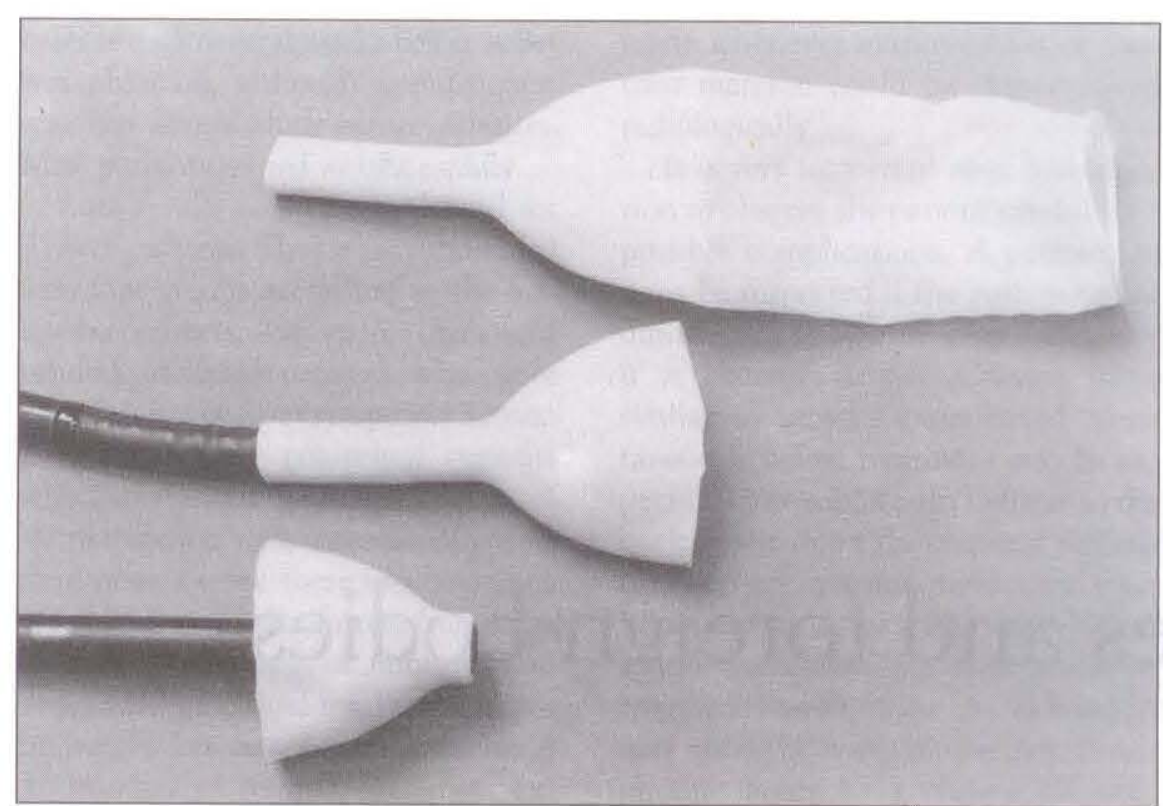

Figure 1) Rubber hood made from condom catheter

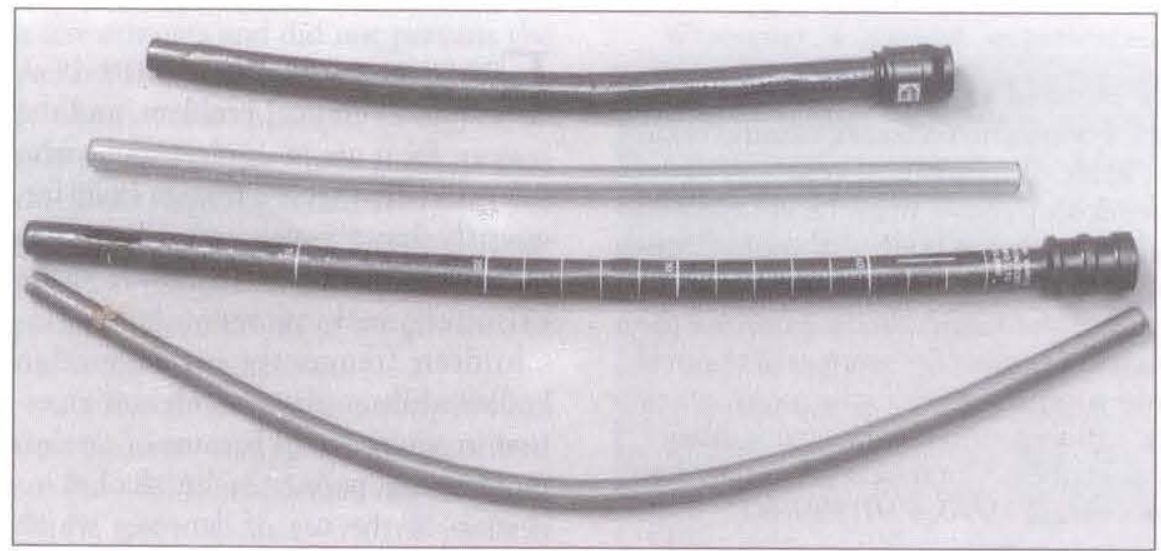

Figure 2) Examples of commercially available overtubes

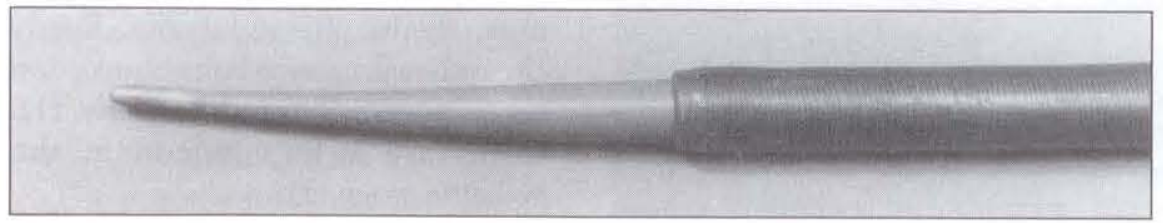

Figure 3) Overtube passed with Maloney bougie acting as a rail

require general anesthesia especially where airway protection may be compromised.

When managing a patient with a foreign body, some basic questions must be addressed. Is the object likely to cause obstruction and/or perforation? Can it be safely removed endoscopically without further damage to the gut or hypopharynx, and without causing airway obstruction? From an endoscopic point of view, what goes down can usually come up. Radiological examination should be carried out beforehand to determine the location of the object and whether it has moved.

Nonradiopaque objects such as toothpicks or glass will not be seen. For some unusually shaped objects a practice session with a similarly shaped foreign body should be tried.

Prior to endoscopy there should be available a selection of snares, alligator forceps, baskets, three-pronged graspers, a condom hood (Figure 1) and an overtube (Figure 2,3). Overtubescan either be made from tygon plastic tubing or purchased commercially from Carsen Medical and Scientific (Toronto) or Mui Scientific (Toronto). Condom hoods are made from readily available condom catheters. The filamentous part of the catheter is trimmed off and the rubber end slipped over a similar sized endoscope and tied with a silk ligature. The 'tulip' is then pulled back over the end of the endoscope to prepare for intubation. The tulip is everted when pulled up from the stomach into the esophagus, or when pulled back from the duodenum.

A number of studies have shown that the one area which mandates prompt removal of a foreign body is the esophagus $(4,5)$. Most esophageal foreign bodies lodge at one of four primary sites: the level of the cricopharyngeus muscle; the level of the aortic arch and its mainstem bronchus; the esophago gastric junction; and pathological sites of narrowing. Here the complications of impaction with edema and necrosis and resultant perforation and its subsequent mediastinal consequences are much more serious than in the abdomen. Petforations tend to occur when foreign bodies remain lodged for prolonged periods ( 24 to $36 \mathrm{~h}$ ) (6).

Of foreign bodies reaching the stomach, at least $80 \%$ will pass spon. taneously within a range of $24 \mathrm{~h}$ to 10 days (7). Only 2 to $5 \%$ will require laparotomy for removal because of either impending impaction, obstruc. tion, perforation or hemorrhage (8).

Some foreign bodies seem to carrya higher risk of perforation, eg, chicken bones and toothpicks (9). Although some physicians advocate observation on the premise that most foreign bodies will pass safely, prolonged observation is required which can lead to unneces. sary anxiety. Under these circumstances, if the foreign body is in the stomach, there is some advantage to removing it promptly by endoscopy. Certainly in cases where there is a higher risk of entrapment, such as prior intestinal disease, strictures as in 
Crohn's disease or known diverticular disease, an earlier attempt at endoscopic removal from the stomach should be made (9-11). Sharp objects or objects longer than $5 \mathrm{~cm}$ should be removed endoscopically as they will seldom leave the stomach (12).

Once the foreign body is beyond the distal duodenum, the most that can be done is to wait and follow with serial $\mathrm{x}$-rays. A surprising number will pass spontaneously.

\section{COMMON FOREIGN BODIES AND THEIR REMOVAL}

A blockage caused by meat in the esophagus usually occurs at an anatomical narrowing or a pathological site. The food is usually poorly chewed and impaction at a tree of stricture, Schatzke's ring, diverticulum or achalasia is not uncommon. Bolus obstruction has occurred in a number of patients with post sclerotherapy stricture. If the piece of meat is large, one should endeavour to remove it whole with a polypectomy snare to avoid the problems which arise with shredding. The bolus is pulled up to the endoscope and then out.

The upper sphincter is the main area of concern at which to lose the bolus. The endoscopist should be prepared to insert his index finger under the endoscope and lift up in the direction of the hypopharynx. This will usually bring the foreign body out safely. Where there is fragmentation of the meat and multiple passages of the endoscope are required, the use of an overtube is mandatory. As the bolus decreases in size it may be possible to push it through into the st mmach. The author tends not to use digestants such as papain to soften an esophageal bolus. In some patients general anesthesia may be necessary to protect the airway.

Bones, shells and foreign bodies with irregular edges such as chicken bones have a relatively high incidence of perforation. They are usually removed with a snare, with or without the overtube or condom hood.

Bezoars are usually associated with an anatomical or motility problem. The lesion may be disrupted endoscopically using forceps or a snare. A papain solu- tion is helpful, followed by a clear fluid diet and prokinetic agents to facilitate passage out of the stomach. An overtube and frequent endoscopic passages may hasten removal of the bezoar.

Glass, bottle tops and other sharps should be grasped with the snare and extracted with either an overtube or a condom hood. Coins may be removed either with alligator-type forceps or a Dormer basket. Foreign bodies with holes, such as rings or buttons, can be removed with biopsy forceps or balloon dilators inflated in the lumen of the foreign body.

Pencils, pens, wires and thermometers, if long and sharp, should be removed immediately, especially if the object is longer then $5 \mathrm{~cm}$. This is best done with an overtube.

Feeding gastrostomy tubes are usually removed without difficulty - the outside connection is severed with scissors and a snare applied. Occasionally the spout will become impacted and embedded in the gastric wall. A mini-snare or alligator forceps will be required, with considerable pull and force.

Removal of obesity balloons is sometimes more problematic, but is obviously a decreasing problem as few obesity balloons are now placed. The tube must be deflated with a puncture which can be done using either a sclerosing catheter or any cautery device, including laser. Once the balloon is deflated, it can then be secured with a snare and removed.

Safety pins and razor blades (usually halves) are removed with the snare or alligator forceps and drawn up into an overtube or condom hood.

Alkaline button battery ingestion is a unique problem in childhood (12-14). Damage to batteries by gastric and intestinal juices can lead to release of caustic chemicals with resulting perforation. However, $90 \%$ pass eventually. If lodged in the esophagus, endoscopy should be performed promptly; if in the stomach for more than two to three days, remove endoscopically.

Cocaine may be concealed in swallowed packets. Rupture of these packets can be fatal. Because of the danger of damage to the packet with endoscopy, surgical removal is advocated (15-17).

At times a patient will believe that he has swallowed a chicken fish bone or a minute, sharp object and feel a scratching or painful sensation in the pharynx or retrosternally. Careful examination of the pharynx and vocal cords is essential. If this fails to locate the foreign body, a contrast study or xeroradiography may be required, which offers superior soft tissue contrast of the neck. Most resolve in a few days.

Overtubes should not be passed blindly, but always advanced over the endoscope as over a rail. An overtube can be passed with a Maloney-or Hursttype bougie of appropriate size. Once in the esophagus, the bougie is removed and the endoscope passed. Experience and clinical circumstances will determine whether the overtube should be passed into the stomach, or whether the foreign body should be pulled up through the gastroesophageal junction and then into the overtube. One of the disadvantages of the overtube is that one loses air and hence the ability to distend the organ. With spoons the snare must be placed around the proximal end so that the spoon is not caught at the gastroesophageal junction. Pulling it into the overtube then facilitates relaxation of the sphincter and it can be safely removed.

Most colon and rectal foreign bodies seem to occur in homosexuals and may require general anesthetic or a perianal block to relax the sphincter.

\section{COMPLICATIONS}

There is little in the literature concerning complications of foreign body ingestion and its endoscopic removal. The risk of upper endoscopic perforation is approximately one in 1000 for routine endoscopy, 4.3 in 1000 for mercury tube dilators, and six in 1000 for the Eder-Puestow-type dilator. With careful and experienced endoscopy, perforation related to foreign body removal should be rare.

\section{REFERENCES}

1. Rosch W, Classen M. Fiberendoscopic foreign body removal from the uppergastrointestinal tract. Endoscopy 1972;4:193-7.

2. Webb WA, McDaniel L, Jones L. 
Foreign bodies of the upper gastrointestinal tract: Current management. South Med J 1984;77:1083-6.

3. Erbes J, Babbitt DP. Foreign bodies in the alimentary tract of infants and children. Appl Ther 1965;7:1103-9.

4. Maleki M, Evans WE. Foreign body perforation of the intestinal tract. Arch Surg 1970;101:475-7.

5. Spitz L. Management of ingested foreign bodies in childhood. Br Med J 1971;4:469-72.

6. Chaikhouni A, Kratz JM, Crawford FA. Foreign bodies of the esophagus. Am Surg 1985;51:173-9.

7. Schwartz GF, Polsky HS. Ingested foreign bodies of the gastrointestinal tract. Am Surg 1976;42:236-8.

8. Pereiman H. Toothpick perforation of the gastrointestinal tract. J Abdom Surg 1962;4:51-3.

9. Schwartz JT, Graham DY. Toothpick perforation of the intestines. Ann Surg 1977;185:64-6.

10. McPherson RD, Karlan M, Williams RD. Foreign body perforation of the intestinal tract. Am J Surg 1975;94:564-6.

11. Vemula NR, Madriaga J, Brand J, et al. Colonoscopic removal of a foreign body causing colocutaneous fistula. Gastrointest Endosc 1982;28:195-6.

12. Litovitz TL. Battery ingestions product accessibility and clinical course.
Pediatrics 1985;75:469-76.

13. Votteler TP, Nash JC, Rudledhe JC. The hazard of ingested alkaline disk batteries in children. JAMA 1983;249:2504-6.

14. Temple DM, McNeese MC. Hazards of battery ingestion. Pediatrics 1983;71:100-3.

15. Suarez CA, Arango A, Lester JL. Cocaine-condom ingestion: Surgical treatment. JAMA 1977;238:1391-2

16. Caruana DS, Weinbach B, Goerg D,et al. Cocaine packet ingestion. Ann ln. tern Med 1984;100:73-4.

17. McCarron MM, Wood JD. The cocaine 'body packet' syndrome. JAMA 1983;250:1417-20. 


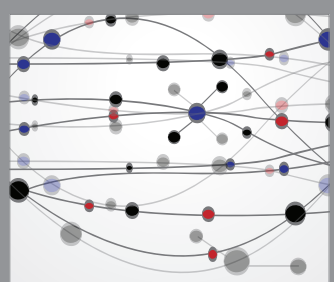

The Scientific World Journal
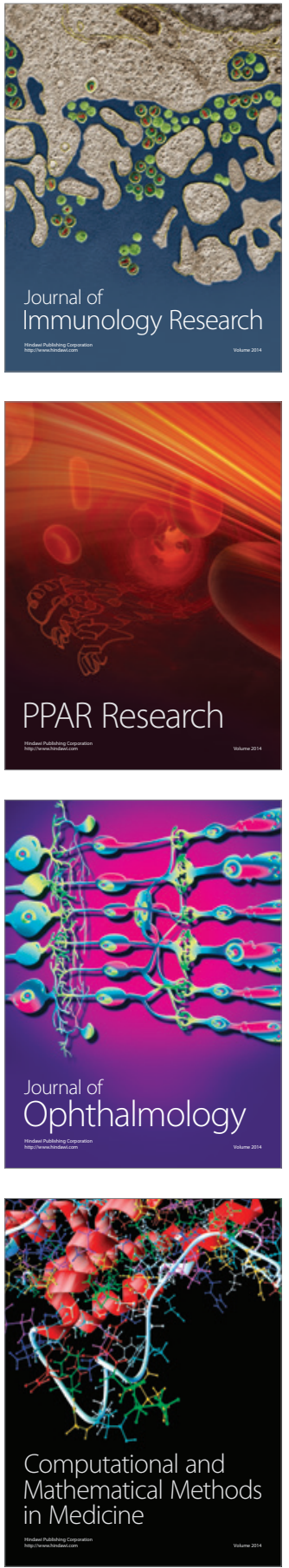

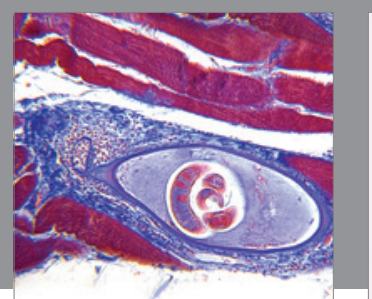

Gastroenterology Research and Practice

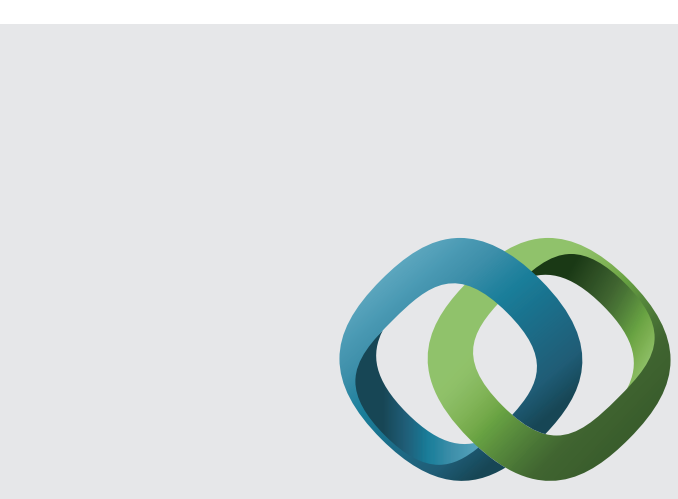

\section{Hindawi}

Submit your manuscripts at

http://www.hindawi.com
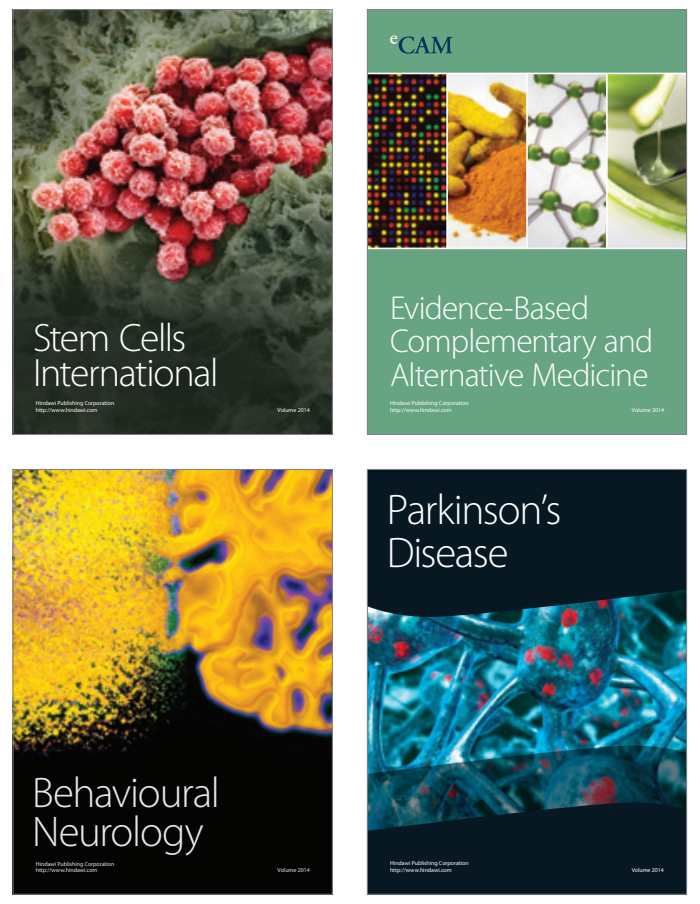
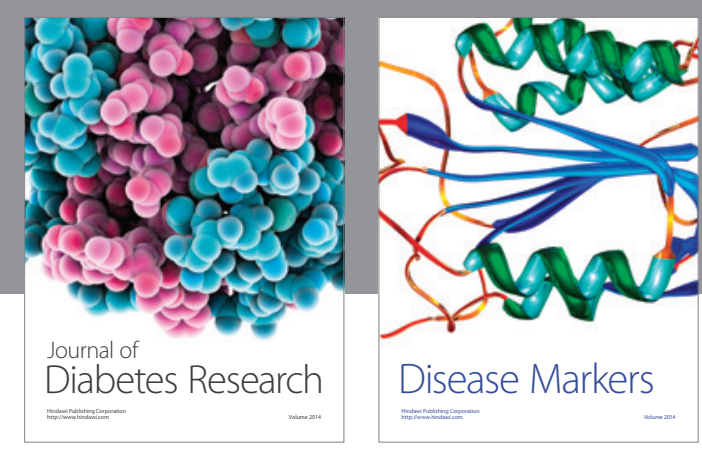

Disease Markers
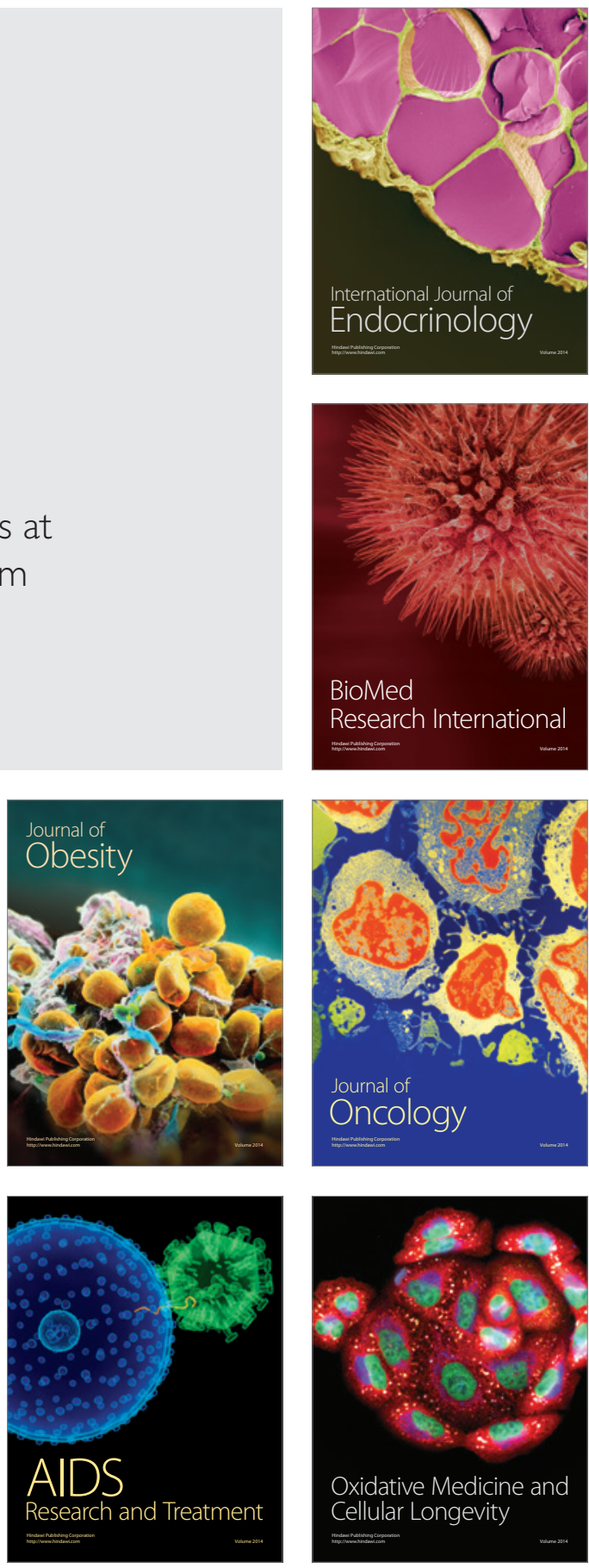